\title{
Medication Use among Veterans across Health Care Systems
}

Khoa A. Nguyen 1,2; David A. Haggstrom ${ }^{1,4,5}$; Susan Ofner ${ }^{3}$; Susan M. Perkins ${ }^{3}$; Dustin D. French ${ }^{6}$; Laura J. Myers ${ }^{1}$; Marc Rosenman ${ }^{8}$; Michael Weiner ${ }^{1,5,7}$; Brian E. Dixon ${ }^{1,4,5}$; Alan J. Zillich ${ }^{1,2}$

${ }^{1}$ Center for Health Information and Communication, Department of Veterans Affairs (VA), Veterans Health Administration, Health Services Research and Development Service (CIN 13-416), Richard L. Roudebush VA Medical Center, Indianapolis, IN, USA; ${ }^{2}$ College of Pharmacy, Purdue University, West Lafayette, IN, USA;

${ }^{3}$ Department of Biostatistics, School of Medicine, Indiana University, IN, USA;

${ }^{4}$ Department of Medicine, Indiana University School of Medicine, Indianapolis, IN, USA;

${ }^{5}$ Regenstrief Institute, Inc., Indianapolis, IN, USA;

${ }^{6}$ Department of Ophthalmology and the Center for Healthcare Studies, Feinberg School of Medicine, Northwestern University, and the Veterans Affairs Health Services Research and Development Service, in Chicago, IL, USA;

${ }^{7}$ Indiana University Center for Health Services and Outcomes Research, Indianapolis, IN, USA;

${ }^{8}$ Department of Pediatrics, Children's Health Services Research, Indiana University, Regenstrief Institute, Inc.

\section{Keywords \\ Medication use, health information exchange, medication safety, dual health care systems}

\section{Summary}

Introduction: Dual healthcare system use can create gaps and fragments of information for patient care. The Department of Veteran Affairs is implementing a health information exchange (HIE) program called the Virtual Lifetime Electronic Record (VLER), which allows providers to access and share information across healthcare systems. HIE has the potential to improve the safety of medication use. However, data regarding the pattern of outpatient medication use across systems of care is largely unknown. Therefore, the objective of this study is to describe the prevalence of medication dispensing across VA and non-VA health care systems among a cohort Veteran population Methods: This study included all Veterans who had two outpatient visits or one inpatient visit at the Indianapolis VA during a 1-year period prior to VLER enrollment. Source of medication data was assessed at the subject level, and categorized as VA, INPC (non-VA), or both. The primary target was identification of sources for medication data. Then, we compared the mean number of prescriptions, as well as overall and pairwise differences in medication dispensing.

Results: Out of 52,444 Veterans, $17.4 \%$ of subjects had medication data available in a regional HIE. On average, 40 prescriptions per year were prescribed for Veterans who used both sources compared to 29 prescriptions per year from VA only and 25 prescriptions per year from INPC only sources. The annualized prescription rate of Veterans in the dual use group was $36 \%$ higher than those who had only VA data available and $61 \%$ higher than those who had only INPC data available.

Conclusions: Our data demonstrated that $17.4 \%$ of subjects had medication use identified from non-VA sources, including prescriptions for antibiotics, antineoplastics, and anticoagulants. These data support the need for HIE programs to improve coordination of information, with the potential to reduce adverse medication interactions and improve medication safety. 


\section{Correspondence to:}

Khoa A Nguyen, Pharm.D

Medical Informatics Postdoctoral Fellow

VA HSR\&D-CHIC, D6004-2

1481 West 10th Street, Indianapolis, IN 46202, USA

Email: khoa.nguyen6@va.gov

Phone: (317) 988-4409
Appl Clin Inform 2017; 8: 235-249

https://doi.org/10.4338/ACI-2016-10-RA-0184

received: October 26, 2016

accepted: January 6, 2017

published: March 8, 2017

Citation: Nguyen KA, Haggstrom DA, Ofner S, Perkins $S M$, French DD, Myers LJ, Rosenman M, Weiner M, Dixon BE, Zillich AJ. Medication use among veterans across health care systems. Appl Clin Inform 2017; 8: 235-249

https://doi.org/10.4338/ACI-2016-10-RA-0184

Funding

This project was supported by the U.S. Department of Veterans Affairs (VA) Health Services Research and Development (HSR\&D) Service, grant number IIR 11-058, Evaluation of VLER Indiana Health Information Exchange Demonstration Project. This work was further supported by VA HSR\&D grant CIN 13-416 at the Richard L. Roudebush Veterans Affairs Medical Center in Indianapolis, Indiana. Dr. Weiner is Chief of Health Services Research and Development at the Richard L.

Roudebush Veterans Affairs Medical Center in Indianapolis, Indiana.

The views expressed in this article are those of the authors and do not necessarily represent the views of the Department of Veterans Affairs. 


\section{Introduction}

Dual health care system use is common for most US Veterans, especially Veterans aged 65 years or older [1]. According to Wolinsky and colleagues, dual use of health care systems can have both positive and negative effects [2]. Although it may improve choice for Veterans, a top priority for the Veterans Health Administration, dual use can create fragmentation of care and gaps in critical health information. Importantly, when healthcare providers from different health systems do not have the tools to access information about care provided in "the other system," dual use can affect quality of care and safety. In an ongoing effort to improve the sharing of health information across systems of care, the Veterans Health Administration (VHA) created the Virtual Lifetime Electronic Record (VLER) Health Initiative [3]. VLER Health is a health information exchange (HIE) platform, which enables physicians and healthcare staff access to patient information, including past and current medications, across VA and private health care systems. As a result, it facilitates access to more complete records of care for Veterans regardless of the location where care is received.

Medication errors are a significant threat to patient safety. Approximately $20 \%$ of medical errors are related to medications $[4,5]$, and medication errors cause at least one death every day and injure more than one million people annually in the U.S. [6]. Most medication errors occur during transitions in care, when reconciliation is subpar, such as when patients are admitted from ambulatory settings to hospitals or discharged from hospitals to ambulatory settings. In many cases, transitions of care errors occur across different health systems that do not utilize HIE to share medication related data [7]. HIE has the potential to improve the safety of medication use through sharing of medication-related data during transitions of care.

Currently, there is mixed evidence on the effectiveness of HIE with respect to safety and outcomes. Hincapie and Warholak demonstrated fewer emergency department visits and better HgbA1c control [8-10]. Similarly, Fontaine and colleagues found HIE improves efficiency, including improved access to outside test results $[11,12]$. However, in a recent study, French et al. found that HIE did not result in short-term cost reductions [13]. Moreover, recent systematic reviews by Rahurkar and Hersh concluded that the current literature does not provide sufficient evidence for the estimated benefits of HIE $[14,15]$. While the quality of evidence is limited, the preponderance of evidence nonetheless suggests HIE has the potential to improve safety and outcomes.

Prior to leveraging of data to improve quality and safety, especially medication safety, health systems must have medication data available in interoperable health information systems. Yet data regarding the pattern of outpatient medication use across systems of care for Veteran patients is largely unknown. Knowledge about the pattern and prevalence of medication use from both VA and nonVA systems is a necessary first step to understanding the capacity for HIE to improve medication safety. The objective of this study is to describe the prevalence of medication dispensing across VA and non-VA health care systems among a cohort of Veteran population.

\section{Methods}

\section{Study Setting}

The Richard L. Roudebush VA Medical Center (RLR VAMC) in Indianapolis, Indiana provides inpatient and both primary and specialized outpatient services to more than 60,000 patients annually. The Indianapolis VAMC is the only tertiary VA facility in Indiana and includes and network of community-based outpatient clinics across central parts of the state. Some Veterans who live near the border with Indiana also use Indianapolis VAMC facilities for their care.

The Indiana Health Information Exchange (IHIE) is one of the largest and longest tenured community-based HIE networks in the U.S. $[16,17]$. IHIE is an Indiana-based not-for-profit corporation that seeks to improve the quality, safety and efficiency of healthcare in the state of Indiana. IHIE exchanges data among over 200 non-VA health care facilities throughout the state of Indiana, including 106 hospitals, 100 physician outpatient practices, pharmacy networks, long term postacute care facilities, laboratories, and radiology centers. The Indiana Network for Patient Care (INPC) is a federated clinical data warehouse or repository in which data from IHIE is stored, in co- 
operation with the Regenstrief Institute. Nearly one million electronic health care transactions are processed every day by IHIE in support of its client services, including clinical results delivery [18], public health reporting $[19,20]$, and coordination of care [21]. The INPC is estimated to cover $80 \%$ of the population living in Indiana plus portions of metropolitan areas that border Indiana near Chicago, Cincinnati, and Louisville. The geographic footprint of INPC is similar to that of the Indianapolis VAMC.

\section{Study Population}

The Indianapolis VAMC implemented the VLER Health platform for HIE between VA and non-VA providers in the IHIE in late 2011. The study cohort includes Veterans, 18 years or older, assigned to the Indianapolis VAMC on the basis of at least 2 outpatient visits or 1 inpatient visit to the facility during a 12-month period prior to HIE enrollment, ending on March 1, 2012. These inclusion criteria identified a Veteran population who could be assigned as receiving care from the VAMC, and thus, were potential enrollees in the VLER Health Initiative. Patient enrollment in VLER was voluntary. Subjects without medication dispensing data during the 2-year period prior to March 2012 were excluded.

\section{Data Sources and Data Collection}

Veterans' electronic health records from Indianapolis VAMC were linked with health records from non-VHA institutions in the INPC. Records were linked using a combination of patient identifiers by a probabilistic algorithm employed in the INPC. The patient-level linkage rate between the VA and INPC was 83\%; that is, 57,067 Veterans had at least one data element in the INPC out of 69,055 Veterans who met our inclusion criteria for assignment to the Indianapolis VAMC.

The medication time period of interest was the two year period prior to enrollment (the medication window). At the patient level, data were obtained about sociodemographics at the enrollment date (age, race, gender, marital status, and rural residence), health status in the year prior to the medication window (Charlson comorbidity index), access at enrollment (insurance type, VA benefits Priority Group, distance from the Indianapolis VAMC) and VA health care utilization (primary and specialty care outpatient visits) in the year prior to the medication window. Insurance type and race were ascertained using both VA and non-VA HIE data. VA benefits Priority Group assignments are based upon disability and income level. The priority group influences the amount of copayment for VA services. Moderate disability is defined as $10-50 \%$ disabling.

Outpatient medication records within the medication window for the cohort were extracted from both VA and INPC data. For INPC, prescription data is collected from two sources: dispensing records from a major urban health care network in central Indiana and SureScripts (a nationwide pharmacy benefits manager). Data elements extracted from both sources included the drug name, dates of fills, daily dose, days' supply, quantity dispensed, dosage form, NDC code, and medication classification categories. For this study, we classified medications using the American Hospital Formulary Service (AHFS) categories (http://www.ahfsdruginformation.com/pt-classification-system. aspx). All individual drugs prescribed for subjects in the cohort were placed into 1 of 14 "first tier" categories based on the AHFS nomenclature Table 1 .

\section{Outcome Measures and Data Analyses}

The primary target of our study was identification of sources for medication data. Source of medication data was assessed at the subject level and categorized into one of three groups: VA data, INPC data, or both. Characteristics of the cohort at enrollment were tested for an overall difference by use of a one-way analysis of variance (ANOVA) model, a Kruskal-Wallis test, or chi-square test as appropriate. Pairwise comparisons were conducted using either means from the ANOVA model, the Wilcoxon rank sum test, or chi-square tests. All pairwise tests used a Bonferroni adjustment to control the type 1 error rate for each subject characteristic.

Prescription rates by sources were another outcome of interest in this study. The annualized number of prescriptions was measured by dividing the number of prescriptions in the two-year peri- 
od by 2 . The mean annualized number of prescriptions was compared between groups by a negative binomial model with a term for subject level source. If a Veteran had the same drug regimens on the same date, only one record was used. If records of same drug regimen and date presented at both VA and non-VA sources, we selected only VA records.

A multivariable multinomial model was used to model the subject level source of medication data. Independent variables selected for inclusion were demographic characteristics, the Charlson comorbidity index, distance to the VHA medical center, VHA benefits, utilization (primary, specialty care, and total visits) and annualized number of prescriptions.

Prevalence of medication usage was also assessed by 14 Tier 1 drug categories.

For each category, chi-square tests were used to assess overall and pairwise differences in prevalence of the three medication sources. Pairwise comparisons were adjusted for multiple comparisons using a Bonferroni adjustment.

\section{Results}

\section{Descriptive}

A total of 57,770 Veterans had at least 1 inpatient or 2 outpatient visits to the Indianapolis VA in the year prior to HIE enrollment, and 52,444 Veterans were included in our study cohort after exclusion criteria were applied ( $\$$ Figure 1). Among this population, we observed the following sources for medication data: 43,321 (82.6\%) of Veterans had prescription data available from the VA only, 1,699 (3.2\%) of Veterans had prescription data available from INPC only, and 7,424 (14.2\%) of Veterans had data available from both the VA and INPC. Table 2 summarizes descriptive information with pairwise comparisons. A majority of Veterans in this cohort were white males aged 50 years or older; $18.5 \%$ of patients were black. Given the large sample size, most demographic characteristics were significantly different between the three groups. However, some key descriptive findings are worth noting. The mean distance (in miles) from home to the VAMC was not significantly different among those who had data available from both the VA and INPC (35.2 miles) and those who had prescription data from INPC only (24.2; $\mathrm{p}=0.7)$, whereas Veterans with prescription data from VA only were significantly different, on average 72.6 miles from home to the VA $(\mathrm{p}<0.0001)$. Additionally, the proportions of Veterans with one, or two or more co-morbid conditions among those who had prescription data available from either the VA only or both systems were not significantly different $(p=0.2)$; whereas Veterans in the INPC only group had significantly fewer co-morbid conditions $(\mathrm{p}<0.0001)$.

\section{Number of prescriptions}

Table 3 summarizes the annualized number of prescriptions by subject level source (Dual source vs VA only vs. INPC only). The annualized prescription rate in the dual source group was higher than those Veterans who had medication data available from VA alone (IR: 1.36, 95\% CI: 1.33 to $1.39, \mathrm{p}<0.0001$ ) and INPC alone (IR: $1.61,95 \% \mathrm{CI}: 1.54$ to $1.69, \mathrm{p}<0.0001$ ), respectively. On average, 40 prescriptions per year were prescribed for Veterans who had medication data available from dual sources compared to approximately 29 prescriptions per year from VA only sources and 25 prescriptions per year from INPC only sources. Based on the AHFS nomenclature, anti-infectives, antineoplastics, and anticoagulants/blood modifiers $(17.5 \%, 15.4 \%$, and $11.8 \%$, respectively) are the three classes of drugs with the highest percentages of subjects getting their prescriptions outside the VA system. A summary of all AHFS categories and their distributions can be found in $>$ Table 4 . A non-significant proportion of dual source patients received analgesics (including NSAIDs and opioids), respiratory, vitamins/minerals, and other medications compared to INPC use only source.

\section{Multinomial Model}

While $>$ Table 2 provides descriptive information with pairwise comparisons, $>$ Table 5 provides a multivariable multinomial regression model for adjusted comparisons to better estimate the effect of 
patient factors on the association with different sources of medication data. Compared to male Veterans, female Veterans were more likely to have data from both systems than the VA alone (OR 1.46, 95\% CI: 1.32 to $1.63, \mathrm{p}<0.001$.) Black Veterans were more likely than White veterans to have data available from both systems than from only the VA (OR $1.38,95 \%$ CI 1.29 to $1.48, \mathrm{P}<0.0001)$. Veterans who had commercial insurance were more likely than those with government insurance only to have prescription data available from both systems (OR: 2.07, 95\% CI: 1.94 to $2.21, \mathrm{P}<0.0001$ ). Veterans with moderate disability were more likely than veterans with no disability to have data from both systems than from the VA only (OR: 1.15, 95\% CI: 1.07 to $1.25, \mathrm{P}=0.0003$ ). Veterans who were catastrophically disabled or had Medicaid were more likely to have medication data from the VA only than from both systems.

From that same model we found that veterans older than 40 and less than 50 years old had a higher odds of having data available in INPC only over VA only source than veterans $<40$ years old (OR 1.50, 95\% CI: 1.19-1.18). Veterans older than 65 years old were even more likely to have data available from INPC only than VA only (OR: 2.91, 95\% CI: 2.34 to 3.62, P<0.0001). Similarly, female Veterans were significantly more likely to have data available in INPC only than in VA only (OR $1.91,95 \%$ CI 1.54 to $2.37, \mathrm{P}<0.0001$ ). Veterans who have commercial insurance (OR: $2.20,95 \% \mathrm{CI}$ 1.93 to $2.51, \mathrm{P}=<0.0001$ ) or moderate disability (OR: $1.67,95 \%$ CI 1.44 to $1.94, \mathrm{P}<0.0001$ ) were also more likely to have data in INPC only over only in the VA data source than veterans without disability.

\section{Discussion}

Prior to enrollment in VLER Health, 17.4\% of Veterans in our sample had evidence of prescriptions from non-VA sources, including prescriptions for antibiotics (17.5\%), antineoplastics (15.4\%), and anticoagulants (11.8\%), not captured within VA electronic health records. These results complement findings by Stroupe and colleagues [22] who surveyed Medicare-eligible Veterans ( $\geq 65$ years old). Their study found $30.1 \%$ of prescriptions were obtained from both VA and non-VA sources in which heart disease, hypertension, and diabetes were the three most common classes prescribed from non-VA sources. While Stroup's study focused solely on Medicare-eligible Veterans, our study expanded to include both Veterans who were eligible for Medicare, as well as younger Veterans who were not. In fact, $67.7 \%$ of Veterans included in our medication cohort were younger than 65 years old, and thus, were ineligible for Medicare (unless receiving social security disability or dialysis). Compared to Medicare-eligible Veterans who could benefit from Part-D drug coverage, these "younger" Veterans may have less choice to obtain medications from outside sources. Taken together, these studies suggest that the most common classes of medication prescribed vary by age and data source. Importantly, the substantial volume of non-VA medication data observed in this study highlights clinical situations, involving prescriptions from multiple institutions, wherein medication errors have the potential to occur.

For example, our results suggest that the percentage of prescriptions for antineoplastics is exceptionally high from non-VA sources compared to other classes of medications. This is most likely due to a high percentage of Veterans being treated at the NCI-designated Cancer Center of the Indianapolis VA's university affiliate. Methotrexate, hydroxyurea, and fluorouracil, in particular, were medications that have the most data from non-VA sources. This high percentage of medications with significant adverse effect profiles can potentially have a negative effect on Veterans' safety when use of these drugs across systems of care is not well-communicated. Similarly, anticoagulants have a highrisk safety profile with the potential to cause bleeding in patients. Warfarin, in particular, has a limited therapeutic window, requires close monitoring, and is associated with many drug-drug interactions. Therefore, in order for providers to fully monitor patients' outcomes, prescribing information about these medications should be available across systems of care. Additionally, prescribing of antibiotics outside the VA can increase the risk for patients because antibiotic use history, when not shared, may contribute to antimicrobial resistance as well as allergic reactions which can impact outcomes [23]. In fact, a recent study by Shehab and colleagues indicated that adverse drug events from medication classes similar to our study (anticoagulants, antibiotics, and diabetes agents) were implicated in $46.9 \%$ of emergency visits; these adverse drug events ranged from events such as hemor- 
rhage while taking anticoagulants to severe allergic reactions with antibiotics [24]. Certainly, the pattern of medication use in this study across healthcare systems highlights the need for vigilance regarding medication safety and suggests that HIE has potential to improve associated health outcomes.

Our data also showed that patients receiving medications from both VA and non-VA sources appear to have more complex medical needs, as reflected by a higher comorbidity score and a greater annualized number of medications. These dual users have more complex medication needs for several reasons. First, a higher Charlson Comorbidity Score indicated that these Veterans had a greater disease burden. Due to the need to obtain specialty care medications that were not easily available from the VHA prescription formulary, these Veterans with greater comorbidity may then become dual users. Second, compared to other medication classes, medications for two classes (cardiovascular and hypoglycemic) were more likely to be prescribed to dual users. This finding suggests that in order to obtain the treatments they need, patients with chronic medical conditions, such as cardiovascular disease (either acute or chronic) or diabetes, might, again, need to seek medications from multiple sources. The increase in medication use among Veterans using more than one health system may also indicate overuse of similar medications and increased healthcare costs. Indeed, in a study by Gellad's and colleagues [10], Veterans who used VA and non-VA healthcare systems had significantly greater overuse of diabetes test strips and related increases in costs. [26] While their study did not compare the severity of diabetes among healthcare systems, it supports the idea that waste and inefficiency must be addressed for dual use Veterans. Overall, these findings highlight the need for programs like VLER to share medication use data across multiple healthcare systems to both improve patient outcomes and reduce costs.

The consequences of inadequate communication between providers across systems upon quality and health outcomes are of widespread concern [26]. Indeed, many non-VA providers believed that poor communication among VA and non-VA primary care providers, addressed in Gaglioti's study, led to poor patient outcomes [27]. VLER Health and other types of HIE can help close the information gap across healthcare systems. When piloted, the VLER Health program received positive feedback for its effort to reduce information fragmentation [28]. In a report by Byrne and colleagues, VLER Health proved to be accepted, trusted, and perceived of high value by both Veterans and VA providers (90\% of all providers and Veterans trusted VLER). There has also been steady growth in the number of providers using the VLER program [28]. However Lyle et al. identified several issues during the pilot phase of VLER Health, including low data richness and quality scores [29]. Nevertheless, both authors agreed that ongoing, long-term studies of VLER Health are required to assess its full impact $[28,29]$.

Overall, HIEs have great potential to improve health outcomes through information sharing, as well as the provision of clinical decision support leveraging the shared information. For example, existing and new medication reconciliation and interaction tools should be applied across a Veteran's full medication record (not only VA data). Future studies are needed to empirically test if, under what circumstances, and through what mechanisms, HIEs can improve medication related outcomes.

\section{Limitations}

There are several limitations to this study. First, only patients using a pharmacy benefits program managed by SureScripts, or being dispensed prescriptions in a large urban health care network, have non-VA data available in the HIE. This arrangement limits the HIE system's awareness of non-VA medications to those Veterans whose health care providers have relationships with these selected, albeit large, community partners. In addition, $\$ 4$ prescriptions were also available for Veterans during this period of time and were not captured in our study. The $\$ 4$ prescription program allows patients to get certain medications for only $\$ 4$ without insurance information at chain pharmacy stores such as Walmart, Kroger, and CVS. Second, findings from our Midwestern VA HIE demonstration program may not represent medication use experiences from other areas where non-VA use might be more or less; alternatively, HIE partners elsewhere may have more or less medication data. Given the size and scale of the Indiana Health Information Exchange (IHIE), the amount of non-VA data obtained through IHIE here is likely one of the current best case scenarios in the U.S. For the above 
reasons, the true rate of dual use might have been underestimated and may vary in other areas of the country. Nonetheless, our study still highlights the value of additional information obtained regarding non-VA prescriptions from HIE data sources.

\section{Conclusion}

This study demonstrated that, based upon data from a regional HIE demonstration program engaging the VA, $17.4 \%$ of Veterans had medication use identified from non-VA sources, including prescriptions for antibiotics, antineoplastic, and anticoagulants. The large amount of non-VA medication use identified in the HIE is not routinely captured within VA electronic health records. These clinical areas can serve as a focal point for future intervention studies involving HIE, designed to improve the coordination of care. Patients receiving medications from both VA and non-VA sources also appeared to have more complex medical needs, as reflected by their higher comorbidity score and a greater annualized number of medications. These data support the need for HIE programs to improve patient medication-related outcomes among high-risk populations.

\section{Questions}

1. What are three classes of medications that had the highest percentages of subjects getting their prescriptions outside the VA systems?

A Anti-infectives, antineoplastics, and anticoagulants/blood modifiers

B) Analgesics, hypoglycemics, and anti-infectives

C) Analgesics, cardiovascular, and anti-infective

D)Anti-infectives, hypoglycemics, and anticoagulants/blood modifiers

2. What subject level sources (groups) has the highest annualized prescription rate?

A) VA only source

B) Dual source (VA + INPC)

C) INPC only source

\section{Clinical Relevance Statement}

This study is clinical relevance because it describes the prevalence of outpatient medication use for Veterans from both VA and non-VA systems. This information is important to initially assess the capacity for HIE to improve medication safety.

\section{Competing Interests}

There are no conflicts of interest in the research.

\section{Protection of Human and Animal Subjects}

Human and animal subjects were not included in the project 
Eligible for VA HIE Program

Population assigned to Indianapolis

VA with 1 inpatient or 2 outpatient visits $(n=57,770)$

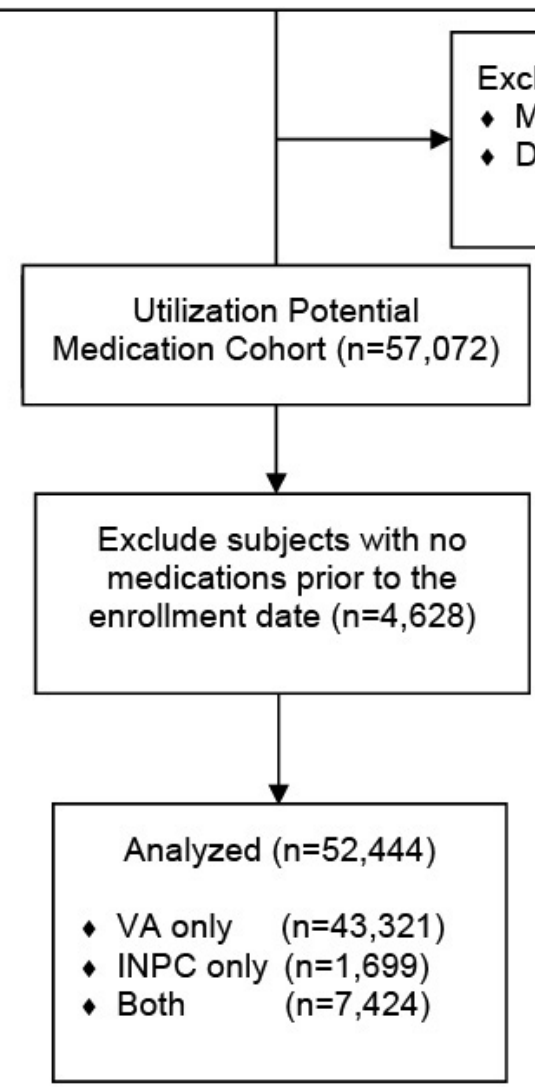

Excluded $(n=698)$

- Missing HIE enrollment date $(n=5)$

- Died prior to HIE enrollment date $(n=693)$ enrollment date $(n=4,628)$

Fig. 1 Flow Diagram of Subject Level Medication Utilization 


\begin{tabular}{|l|}
\hline Category \\
\hline Analgesics \\
\hline Anti-infectives \\
\hline Anticoagulants/Blood Modifiers \\
\hline Antineoplastics \\
\hline Cardiovascular \\
\hline Central Nervous System \\
\hline Dermatological Agents \\
\hline Diabetic Supply \\
\hline Gastrointestinal Medications \\
\hline Hormones/Immunology \\
\hline Hypoglycemics \\
\hline Respiratory \\
\hline Vitamins/Minerals \\
\hline Others \\
\hline
\end{tabular}

*Tier 1 categories were adapted from AHFS nomenclature
Table 1 American Hospital Formulary Service (AHFS) Tier 1 Drug Categories*

Table 2 Baseline Demographics by Subject Level Medication Utilization

\begin{tabular}{|c|c|c|c|c|c|c|c|c|c|}
\hline \multirow{2}{*}{\multicolumn{2}{|c|}{$\begin{array}{l}\text { Data Type and Par- } \\
\text { ameter }\end{array}$}} & \multirow{3}{*}{$\begin{array}{l}\text { Overall } \\
\text { n (\%) } \\
5951(11.3)\end{array}$} & \multicolumn{3}{|c|}{ Subject Level Utilization } & \multirow[b]{2}{*}{$\begin{array}{l}\text { Overall } \\
\text { test } \\
\text { p-value }\end{array}$} & \multicolumn{3}{|c|}{ Pairwise Comparisons } \\
\hline & & & $\begin{array}{l}\text { VA only } \\
\text { n (\%) }\end{array}$ & $\begin{array}{l}\text { Both } \\
\text { n (\%) }\end{array}$ & $\begin{array}{l}\text { INPC only } \\
n(\%)\end{array}$ & & $\begin{array}{l}\text { VA Only } \\
\text { vs. Both }\end{array}$ & $\begin{array}{l}\text { VA Onl } \\
\text { vs. INPC } \\
\text { Only }\end{array}$ & $\begin{array}{l}\text { Both vs. } \\
\text { INPC } \\
\text { only }\end{array}$ \\
\hline \multirow[t]{4}{*}{ Age } & $<40$ & & 5017 (11.6) & $741(10.0)$ & $193(11.4)$ & \multirow[t]{4}{*}{$<0.0001$} & \multirow[t]{4}{*}{0.0002} & \multirow[t]{4}{*}{0.0305} & \multirow[t]{4}{*}{0.1472} \\
\hline & $40-<50$ & 6435 (12.3) & $5215(12.0)$ & $982(13.2)$ & $238(14.0)$ & & & & \\
\hline & $50-<65$ & $23127(44.1)$ & $19151(44.2)$ & $3284(44.2)$ & $692(40.7)$ & & & & \\
\hline & $65+$ & $16931(32.3)$ & 13938 (32.2) & 2417 (32.6) & 576 (33.9) & & & & \\
\hline \multirow[t]{2}{*}{ Gender } & Female & $3756(7.2)$ & $2946(6.8)$ & $643(8.7)$ & $167(9.8)$ & \multirow[t]{2}{*}{$<0.0001$} & \multirow[t]{2}{*}{$<0.0001$} & \multirow[t]{2}{*}{$<0.0001$} & \multirow[t]{2}{*}{0.3802} \\
\hline & Male & $48688(92.8)$ & 40375 (93.2) & $6781(91.3)$ & $1532(90.2)$ & & & & \\
\hline \multirow[t]{3}{*}{ Race } & Black & 9696 (18.5) & 7395 (17.1) & $1935(26.1)$ & $366(21.5)$ & \multirow[t]{3}{*}{$<0.0001$} & \multirow[t]{3}{*}{$<0.0001$} & \multirow[t]{3}{*}{$<0.0001$} & \multirow[t]{3}{*}{0.0010} \\
\hline & $\begin{array}{l}\text { Other/Un- } \\
\text { known }\end{array}$ & $13687(26.1)$ & $13070(30.2)$ & $506(6.8)$ & $111(6.5)$ & & & & \\
\hline & White & 29061 (55.4) & $22856(52.8)$ & $4983(67.1)$ & $1222(71.9)$ & & & & \\
\hline \multirow{3}{*}{ Insurance } & Commercial & $9270(17.7)$ & 5699 (13.2) & $2790(37.6)$ & $781(46.0)$ & \multirow[t]{3}{*}{$<0.0001$} & \multirow[t]{3}{*}{$<0.0001$} & \multirow[t]{3}{*}{$<0.0001$} & \multirow[t]{3}{*}{$<0.0001$} \\
\hline & Government & $20293(38.7)$ & $15783(36.4)$ & $3758(50.6)$ & $752(44.3)$ & & & & \\
\hline & $\begin{array}{l}\text { Other/None/ } \\
\text { Unknown }\end{array}$ & $22881(43.6)$ & $21839(50.4)$ & $876(11.8)$ & $166(9.8)$ & & & & \\
\hline \multirow{3}{*}{$\begin{array}{l}\text { Marital } \\
\text { Status }\end{array}$} & Married & $28182(53.7)$ & 22506 (52.0) & 4647 (62.6) & $1029(60.6)$ & \multirow[t]{3}{*}{$<0.0001$} & \multirow[t]{3}{*}{$<0.0001$} & \multirow[t]{3}{*}{$<0.0001$} & \multirow[t]{3}{*}{$<0.0001$} \\
\hline & Not married & $23761(45.3)$ & $20626(47.6)$ & $2693(36.3)$ & $442(26.0)$ & & & & \\
\hline & Unknown & $501(1.0)$ & $189(0.4)$ & $84(1.1)$ & $228(13.4)$ & & & & \\
\hline \multirow{3}{*}{$\begin{array}{l}\text { Distance } \\
\text { (miles from } \\
\text { home to VA) }\end{array}$} & $\mathrm{N}$ & 52410 & 43290 & 7421 & 1699 & \multirow[t]{3}{*}{$<0.0001$} & \multirow[t]{3}{*}{$<0.0001$} & \multirow[t]{3}{*}{$<0.0001$} & 0.7009 \\
\hline & Mean \pm SD & $65.7 \pm 167.3$ & $72.6 \pm 170.9$ & $35.2 \pm 155.3$ & $24.2 \pm 88.0$ & & & & \\
\hline & $\begin{array}{l}\text { Median (Min, } \\
\text { Max) }\end{array}$ & $30.8(0,8273.2)$ & $42.4(0,8273.2)$ & $11.7(0,4345.1)$ & $12.9(0,1890.3)$ & & & & \\
\hline
\end{tabular}


Table 2 Continued

\begin{tabular}{|c|c|c|c|c|c|c|c|c|c|}
\hline \multirow{2}{*}{\multicolumn{2}{|c|}{$\begin{array}{l}\text { Data Type and Par- } \\
\text { ameter }\end{array}$}} & \multirow{3}{*}{$\begin{array}{l}\text { Overall } \\
\text { n (\%) } \\
1450(2.8)\end{array}$} & \multicolumn{3}{|c|}{ Subject Level Utilization } & \multirow[b]{2}{*}{$\begin{array}{l}\text { Overall } \\
\text { test } \\
p \text {-value }\end{array}$} & \multicolumn{3}{|c|}{ Pairwise Comparisons } \\
\hline & & & $\begin{array}{l}\text { VA only } \\
\text { n (\%) }\end{array}$ & $\begin{array}{l}\text { Both } \\
\text { n (\%) }\end{array}$ & $\begin{array}{l}\text { INPC only } \\
n(\%)\end{array}$ & & $\begin{array}{l}\text { VA Only } \\
\text { vs. Both }\end{array}$ & $\begin{array}{l}\text { VA Onl } \\
\text { vs. INPC } \\
\text { Only }\end{array}$ & $\begin{array}{l}\text { Both vs. } \\
\text { INPC } \\
\text { only }\end{array}$ \\
\hline \multirow[t]{4}{*}{ Location } & $\begin{array}{l}\text { Isolated small } \\
\text { rural city }\end{array}$ & & $1392(3.2)$ & $52(0.7)$ & $6(0.4)$ & \multirow[t]{4}{*}{$<0.0001$} & \multirow[t]{4}{*}{$<0.0001$} & \multirow[t]{4}{*}{$<0.0001$} & \multirow[t]{4}{*}{0.0087} \\
\hline & $\begin{array}{l}\text { Large rural } \\
\text { city }\end{array}$ & 7409 (14.1) & $6931(16.0)$ & $415(5.6)$ & $63(3.7)$ & & & & \\
\hline & $\begin{array}{l}\text { Small rural } \\
\text { city }\end{array}$ & 3338 (6.4) & $3200(7.4)$ & $117(1.6)$ & $21(1.2)$ & & & & \\
\hline & urban & $40247(76.7)$ & $31798(73.4)$ & $6840(92.1)$ & 1609 (94.7) & & & & \\
\hline \multirow{3}{*}{$\begin{array}{l}\text { Service Con- } \\
\text { nected Per- } \\
\text { centage }\end{array}$} & & 25 & 13 & 0 & 12 & \multirow[t]{3}{*}{$<0.0001$} & \multirow[t]{3}{*}{0.0038} & \multirow[t]{3}{*}{$<0.0001$} & \multirow[t]{3}{*}{$<0.0001$} \\
\hline & $\begin{array}{l}\text { Greater than } \\
50 \%\end{array}$ & $10560(20.1)$ & $9003(20.8)$ & $1422(19.2)$ & $135(8.0)$ & & & & \\
\hline & $\begin{array}{l}\text { Less than } \\
50 \%\end{array}$ & $41859(79.9)$ & $34305(79.2)$ & $6002(80.8)$ & $1552(92.0)$ & & & & \\
\hline \multirow{5}{*}{$\begin{array}{l}\text { Enrollment } \\
\text { Priority Score }\end{array}$} & Missing & 639 & 361 & 97 & 181 & \multirow[t]{5}{*}{$<0.0001$} & \multirow[t]{5}{*}{$<0.0001$} & \multirow[t]{5}{*}{$<0.0001$} & \multirow[t]{5}{*}{$<0.0001$} \\
\hline & $\begin{array}{l}\text { Catastrophi- } \\
\text { cally disabled }\end{array}$ & 9011 (17.4) & 7656 (17.8) & $1188(16.2)$ & $167(11.0)$ & & & & \\
\hline & $\begin{array}{l}\text { Moderate } \\
\text { disability }\end{array}$ & $14987(28.9)$ & $11716(27.3)$ & $2582(35.2)$ & $689(45.4)$ & & & & \\
\hline & $\begin{array}{l}\text { Medicaid as- } \\
\text { sistance / low } \\
\text { income }\end{array}$ & $17494(33.8)$ & $15277(35.6)$ & $1894(25.8)$ & $323(21.3)$ & & & & \\
\hline & $\begin{array}{l}\text { No service- } \\
\text { connected } \\
\text { disability }\end{array}$ & $10313(19.9)$ & 8311 (19.3) & $1663(22.7)$ & $339(22.3)$ & & & & \\
\hline \multirow{3}{*}{$\begin{array}{l}\text { Charlson Co- } \\
\text { morbidity } \\
\text { Score }\end{array}$} & 0 & $34389(65.6)$ & $28246(65.2)$ & $4735(63.8)$ & $1408(82.9)$ & \multirow[t]{3}{*}{$<0.0001$} & \multirow[t]{3}{*}{0.1647} & \multirow[t]{3}{*}{$<0.0001$} & \multirow[t]{3}{*}{$<0.0001$} \\
\hline & 1 & 9496 (18.1) & 7930 (18.3) & $1426(19.2)$ & $140(8.2)$ & & & & \\
\hline & $2+$ & 8559 (16.3) & 7145 (16.5) & $1263(17.0)$ & $151(8.9)$ & & & & \\
\hline \multirow{3}{*}{$\begin{array}{l}\text { Primary Care } \\
\text { Visits }\end{array}$} & $\mathrm{N}$ & 52444 & 43321 & 7424 & 1699 & \multirow[t]{3}{*}{$<0.0001$} & \multirow[t]{3}{*}{$<0.0001$} & \multirow[t]{3}{*}{$<0.0001$} & \multirow[t]{3}{*}{$<0.0001$} \\
\hline & Mean \pm SD & $2.7 \pm 3.0$ & $2.8 \pm 3.1$ & $2.3 \pm 2.9$ & $0.4 \pm 1.3$ & & & & \\
\hline & $\begin{array}{l}\text { Median (Min, } \\
\text { Max) }\end{array}$ & $2(0,88)$ & $2(0,88)$ & $2(0,33)$ & $0(0,24)$ & & & & \\
\hline \multirow{3}{*}{$\begin{array}{l}\text { Specialty } \\
\text { Care Visits }\end{array}$} & $\mathrm{N}$ & 52444 & 43321 & 7424 & 1699 & $<0.0001$ & $<0.0001$ & $<0.0001$ & $<0.0001$ \\
\hline & Mean \pm SD & $0.8 \pm 2.2$ & $0.8 \pm 2.3$ & $0.6 \pm 2.0$ & $0.1 \pm 0.6$ & & & & \\
\hline & $\begin{array}{l}\text { Median (Min, } \\
\text { Max) }\end{array}$ & $0(0,125)$ & $0(0,125)$ & $0(0,77)$ & $0(0,18)$ & & & & \\
\hline Total Visits & $N$ & 52444 & 43321 & 7424 & 1699 & $<0.0001$ & $<0.0001$ & $<0.0001$ & $<0.0001$ \\
\hline & Mean \pm SD & $4.5 \pm 5.6$ & $4.7 \pm 5.7$ & $3.9 \pm 5.4$ & $0.8 \pm 2.8$ & & & & \\
\hline & $\begin{array}{l}\text { Median (Min, } \\
\text { Max) }\end{array}$ & $3(0,125)$ & $3(0,125)$ & $2(0,86)$ & $0(0,57)$ & & & & \\
\hline
\end{tabular}


Table 3 Annualized Prescriptions by Subject Level Source

\begin{tabular}{|c|c|c|c|c|c|c|c|c|c|}
\hline & \multirow[t]{2}{*}{ Measure } & \multirow[t]{2}{*}{ Overall } & \multicolumn{3}{|c|}{ Subject Level Source } & \multirow[t]{2}{*}{$\begin{array}{l}\text { Overall } \\
\text { test }\end{array}$} & \multicolumn{3}{|c|}{$\begin{array}{l}\text { Incident Rate Ratio }(95 \% \mathrm{Cl}) \text { and } \\
\text { adjusted p-values }\end{array}$} \\
\hline & & & VA Only & Both & INPC only & & Both vs VA & INPC vs VA & Both vs INPC \\
\hline \multirow{3}{*}{$\begin{array}{l}\text { Number of } \\
\text { prescriptions } \\
\text { per year }\end{array}$} & $\mathrm{n}$ & 52444 & 43321 & 7424 & 1699 & \multirow[t]{3}{*}{$<0.0001$} & \multirow{3}{*}{$\begin{array}{l}1.36 \\
(1.33,1.39) \\
<0.0001\end{array}$} & \multirow{3}{*}{$\begin{array}{l}0.84 \\
(0.81,0.88) \\
<0.0001\end{array}$} & \multirow{3}{*}{$\begin{array}{l}1.61 \\
(1.54,1.69) \\
<0.0001\end{array}$} \\
\hline & Mean \pm SD & $30.6 \pm 28.2$ & $29.3 \pm 27.2$ & $39.8 \pm 31.9$ & $24.6 \pm 27.9$ & & & & \\
\hline & $\begin{array}{l}\text { Median } \\
\text { (Min, Max) }\end{array}$ & $\begin{array}{l}23 \\
(1,349)\end{array}$ & $\begin{array}{l}22 \\
(1,302)\end{array}$ & $\begin{array}{l}32 \\
(1,349)\end{array}$ & $\begin{array}{l}16 \\
(1,275)\end{array}$ & & & & \\
\hline
\end{tabular}

Table 4 Medication Categories by Subject Level Source¥

\begin{tabular}{|c|c|c|c|c|c|c|c|c|}
\hline \multirow[t]{2}{*}{ Super Class } & \multirow{2}{*}{$\begin{array}{l}\text { Overall } \\
\mathrm{n}\end{array}$} & \multicolumn{3}{|c|}{ Within Class: Subject Level Utilization } & \multirow[b]{2}{*}{$\begin{array}{l}\text { Overall } \\
p \text {-value }\end{array}$} & \multicolumn{3}{|c|}{ Pairwise Comparisons } \\
\hline & & $\begin{array}{l}\text { VA Only } \\
\text { n (\%) }\end{array}$ & $\begin{array}{l}\text { Both } \\
\text { n (\%) }\end{array}$ & $\begin{array}{l}\text { INPC Only } \\
\mathrm{n}(\%)\end{array}$ & & $\begin{array}{l}\text { VA vs. } \\
\text { Both }\end{array}$ & $\begin{array}{l}\text { VA vs. } \\
\text { INPC }\end{array}$ & $\begin{array}{l}\text { Both vs. } \\
\text { INPC }\end{array}$ \\
\hline Analgesics & 33380 & $27698(83.0)$ & $2885(8.6)$ & $2797(8.4)$ & $<0.0001$ & $<0.0001$ & $<0.0001$ & 0.7291 \\
\hline Anti-infective & 23645 & $17842(75.5)$ & $1666(7.0)$ & $4137(17.5)$ & $<0.0001$ & $<0.0001$ & $<0.0001$ & $<0.0001$ \\
\hline Anticoagulants/Blood Modifiers & 7917 & $6459(81.6)$ & $527(6.7)$ & $931(11.8)$ & $<0.0001$ & $<0.0001$ & $<0.0001$ & $<0.0001$ \\
\hline Antineoplastics & 1018 & $823(80.8)$ & $38(3.7)$ & $157(15.4)$ & $<0.0001$ & $<0.0001$ & $<0.0001$ & $<0.0001$ \\
\hline Cardiovascular & 40845 & $35147(86.0)$ & $3890(9.5)$ & $1808(4.4)$ & $<0.0001$ & $<0.0001$ & $<0.0001$ & $<0.0001$ \\
\hline Central Nervous System & 28583 & $24594(86.0)$ & $2357(8.2)$ & $1632(5.7)$ & $<0.0001$ & $<0.0001$ & $<0.0001$ & $<0.0001$ \\
\hline Dermatological Agents & 20726 & $18722(90.3)$ & $775(3.7)$ & $1229(5.9)$ & $<0.0001$ & $<0.0001$ & $<0.0001$ & $<0.0001$ \\
\hline Diabetic Supply & 13356 & $12728(95.3)$ & $444(3.3)$ & $184(1.4)$ & $<0.0001$ & $<0.0001$ & $<0.0001$ & $<0.0001$ \\
\hline Gastrointestinal Medications & 30903 & $27338(88.5)$ & $2061(6.7)$ & $1504(4.9)$ & $<0.0001$ & $<0.0001$ & $<0.0001$ & $<0.0001$ \\
\hline Hormones/Immunology & 24730 & $20848(84.3)$ & $1559(6.3)$ & $2323(9.4)$ & $<0.0001$ & $<0.0001$ & $<0.0001$ & $<0.0001$ \\
\hline Hypoglycemics & 14016 & $12251(87.4)$ & $1168(8.3)$ & $597(4.3)$ & $<0.0001$ & $<0.0001$ & $<0.0001$ & $<0.0001$ \\
\hline Respiratory & 11975 & $10472(87.4)$ & $696(5.8)$ & $807(6.7)$ & $<0.0001$ & $<0.0001$ & $<0.0001$ & 0.0126 \\
\hline Vitamins/Minerals & 17736 & $16382(92.4)$ & 691 (3.9) & $663(3.7)$ & $<0.0001$ & $<0.0001$ & $<0.0001$ & 0.9999 \\
\hline Others & 37283 & $33696(90.4)$ & $1864(5.0)$ & $1723(4.6)$ & $<0.0001$ & $<0.0001$ & $<0.0001$ & 0.0557 \\
\hline
\end{tabular}

$¥$ Chi-square tests were used to test for overall and pairwise differences in the percentage of subjects with medications from different sources. For each class, pairwise tests used a Bonferroni adjustment to control the type 1 error. 
Table 5 Multinomial Model Comparisons for Medication Utilization by Source

\begin{tabular}{|c|c|c|c|c|c|c|c|c|c|}
\hline \multirow{3}{*}{\multicolumn{2}{|c|}{ Data Type and Parameter }} & \multicolumn{8}{|c|}{ Multivariable Multinomial Model } \\
\hline & & \multicolumn{4}{|c|}{ Both vs VA Only } & \multicolumn{4}{|c|}{ INPC vs VA Only } \\
\hline & & $\begin{array}{l}\text { Overall } \\
\text { test } \\
\text { P-value }\end{array}$ & P-value & $\begin{array}{l}\text { Odds } \\
\text { Ratio }\end{array}$ & $95 \% \mathrm{Cl}$ & $\begin{array}{l}\text { Overall } \\
\text { test } \\
\text { P-value }\end{array}$ & P-value & $\begin{array}{l}\text { Odds } \\
\text { Ratio }\end{array}$ & $95 \% \mathrm{Cl}$ \\
\hline \multirow[t]{4}{*}{ Age } & $<40$ & \multirow[t]{4}{*}{$<0.0001$} & & reference & & \multirow[t]{4}{*}{$<0.0001$} & & reference & \\
\hline & $40-<50$ & & 0.0531 & 1.12 & $(1.00,1.26)$ & & 0.0005 & 1.50 & $(1.19,1.88)$ \\
\hline & $50-<65$ & & 0.6730 & 1.02 & $(0.92,1.13)$ & & $<0.0001$ & 1.75 & $(1.44,2.13)$ \\
\hline & $65+$ & & 0.4765 & 1.04 & $(0.93,1.16)$ & & $<0.0001$ & 2.91 & $(2.34,3.62)$ \\
\hline \multirow[t]{2}{*}{ Gender } & Male & \multirow[t]{2}{*}{$<0.0001$} & & reference & & \multirow[t]{2}{*}{$<0.0001$} & & reference & \\
\hline & Female & & $<0.0001$ & 1.46 & $(1.32,1.63)$ & & $<0.0001$ & 1.91 & $(1.54,2.37)$ \\
\hline \multirow[t]{3}{*}{ Race } & White & \multirow[t]{3}{*}{$<0.0001$} & & reference & & \multirow[t]{3}{*}{$<0.0001$} & & reference & \\
\hline & Black & & $<0.0001$ & 1.38 & $(1.29,1.48)$ & & 0.2311 & 1.09 & $(0.95,1.26)$ \\
\hline & Other/Unknown & & $<0.0001$ & 0.49 & $(0.44,0.54)$ & & $<0.0001$ & 0.42 & $(0.34,0.53)$ \\
\hline \multirow[t]{3}{*}{ Insurance } & Government & \multirow[t]{3}{*}{$<0.0001$} & & reference & & \multirow[t]{3}{*}{$<0.0001$} & & reference & \\
\hline & Commercial & & $<0.0001$ & 2.07 & $(1.94,2.21)$ & & $<0.0001$ & 2.20 & $(1.93,2.51)$ \\
\hline & $\begin{array}{l}\text { Other/None/Un- } \\
\text { known }\end{array}$ & & $<0.0001$ & 0.25 & $(0.23,0.27)$ & & $<0.0001$ & 0.25 & $(0.21,0.31)$ \\
\hline $\begin{array}{l}\text { Distance (miles } \\
\text { from home to } \\
\text { VA) }\end{array}$ & & $<0.0001$ & $<0.0001$ & 0.98 & $(0.97,0.98)$ & $<0.0001$ & $<0.0001$ & 0.93 & $(0.91,0.95)$ \\
\hline \multirow[t]{4}{*}{$\begin{array}{l}\text { Enrollment } \\
\text { Priority Score }\end{array}$} & $\begin{array}{l}\text { No service con- } \\
\text { nected disability }\end{array}$ & \multirow[t]{4}{*}{$<0.0001$} & & reference & & \multirow[t]{4}{*}{$<0.0001$} & & reference & \\
\hline & $\begin{array}{l}\text { Medicaid_assist- } \\
\text { ance/low_income }\end{array}$ & & $<0.0001$ & 0.62 & $(0.57,0.67)$ & & $<0.0001$ & 0.59 & $(0.50,0.70)$ \\
\hline & $\begin{array}{l}\text { Catastrophi- } \\
\text { cally_disabled }\end{array}$ & & $<0.0001$ & 0.62 & $(0.57,0.68)$ & & 0.3157 & 0.90 & $(0.73,1.11)$ \\
\hline & $\begin{array}{l}\text { moderate_dis- } \\
\text { ability }\end{array}$ & & 0.0003 & 1.15 & $(1.07,1.25)$ & & $<0.0001$ & 1.67 & $(1.44,1.94)$ \\
\hline \multirow{3}{*}{$\begin{array}{l}\text { Charlson } \\
\text { Co-morbidity } \\
\text { Score }\end{array}$} & 0 & \multirow[t]{3}{*}{0.0159} & & reference & & \multirow[t]{3}{*}{0.0159} & & reference & \\
\hline & 1 & & 0.1540 & 0.95 & $(0.88,1.02)$ & & 0.0347 & 0.81 & $(0.66,0.98)$ \\
\hline & $2+$ & & 0.0323 & 0.91 & $(0.84,0.99)$ & & 0.2453 & 1.13 & $(0.92,1.38)$ \\
\hline $\begin{array}{l}\text { Annual Number } \\
\text { of Prescriptions }\end{array}$ & & $<0.0001$ & $<0.0001$ & 1.02 & $(1.02,1.02)$ & $<0.0001$ & $<0.0001$ & 1.01 & $(1.01,1.02)$ \\
\hline $\begin{array}{l}\text { Primary Care } \\
\text { Visits }\end{array}$ & & $<0.0001$ & $<0.0001$ & 0.90 & $(0.89,0.92)$ & $<0.0001$ & $<0.0001$ & 0.29 & $(0.26,0.32)$ \\
\hline $\begin{array}{l}\text { Specialty Care } \\
\text { Visits }\end{array}$ & & $<0.0001$ & $<0.0001$ & 0.94 & $(0.91,0.96)$ & $<0.0001$ & $<0.0001$ & 0.67 & $(0.59,0.77)$ \\
\hline Total Visits & & $<0.0001$ & $<0.0001$ & 0.97 & $(0.96,0.99)$ & $<0.0001$ & 0.6078 & 0.99 & $(0.96,1.02)$ \\
\hline
\end{tabular}




\section{References}

1. Humensky J, Carretta H, de Groot K, Brown MM, Tarlov E, Hynes DM. Service utilization of veterans dually eligible for VA and Medicare fee-for-service: 1999-2004. Medicare \& medicaid research review 2012; 2(3). doi: 10.5600/mmrr.002.03.a06. PubMed PMID: 24800148; PubMed Central PMCID: PMC4006386.

2. Wolinsky FD, Miller TR, An H, Brezinski PR, Vaughn TE, Rosenthal GE. Dual use of Medicare and the Veterans Health Administration: are there adverse health outcomes? BMC health services research 2006; 6: 131. doi: 10.1186/1472-6963-6-131. PubMed PMID: 17029643; PubMed Central PMCID: PMC1617101.

3. VLER Health: VA Health Care; [cited 2015 10/28]. Available from: http://www.va.gov/VLER/about-vlerhealth.asp\#what-is-vler-health.

4. Gandhi TK, Weingart SN, Borus J, Seger AC, Peterson J, Burdick E, Seger DL, Shu K, Federico F, Leape LL, Bates DW. Adverse drug events in ambulatory care. The New England journal of medicine 2003; 348(16): 1556-1564. doi: 10.1056/NEJMsa020703. PubMed PMID: 12700376.

5. Gandhi TK, Burstin HR, Cook EF, Puopolo AL, Haas JS, Brennan TA, Bates DW. Drug complications in outpatients. Journal of general internal medicine 2000; 15(3): 149-154. PubMed PMID: 10718894; PubMed Central PMCID: PMC1495358.

6. U.S. Food and Drug Administration. Medication error reports: FDA; 2009 [updated 03/05/2009; cited 2016 06/06]. Available from: http://www.fda.gov/Drugs/DrugSafety/MedicationErrors/ucm080629.htm.

7. Johnson A, Guirguis E, Grace Y. Preventing medication errors in transitions of care: A patient case approach. Journal of the American Pharmacists Association: JAPhA 2015; 55(2): e264-e274; quiz e75-e76. doi: 10.1331/JAPhA.2015.15509. PubMed PMID: 25749270.

8. Hincapie A, Warholak T. The impact of health information exchange on health outcomes. Applied clinical informatics 2011; 2(4): 499-507. doi: 10.4338/ACI-2011-05-R-0027. PubMed PMID: 23616891; PubMed Central PMCID: PMC3612997.

9. Vest JR, Kern LM, Silver MD, Kaushal R, investigators H. The potential for community-based health information exchange systems to reduce hospital readmissions. Journal of the American Medical Informatics Association: JAMIA. 2015; 22(2): 435-442. doi: 10.1136/amiajnl-2014-002760. PubMed PMID: 25100447.

10.Gellad WF, Zhao X, Thorpe CT, Mor MK, Good CB, Fine MJ. Dual use of Department of Veterans Affairs and medicare benefits and use of test strips in veterans with type 2 diabetes mellitus. JAMA internal medicine 2015; 175(1): 26-34. doi: 10.1001/jamainternmed.2014.5405. PubMed PMID: 25383920.

11. Fontaine P, Ross SE, Zink T, Schilling LM. Systematic review of health information exchange in primary care practices. Journal of the American Board of Family Medicine: JABFM 2010; 23(5): 655-670. doi: 10.3122/jabfm.2010.05.090192. PubMed PMID: 20823361.

12. Vest JR, Kaushal R, Silver MD, Hentel K, Kern LM. Health information exchange and the frequency of repeat medical imaging. The American journal of managed care. 2014; 20(11 Spec No. 17): eSP16-eSP24. PubMed PMID: 25811815.

13. French DD, Dixon BE, Perkins SM, Myers LJ, Weiner M, Zillich AJ, Haggstrom DA. Short-Term Medical Costs of a VHA Health Information Exchange: A CHEERS-Compliant Article. Medicine 2016; 95(2): e2481. doi: 10.1097/MD.0000000000002481. PubMed PMID: 26765453; PubMed Central PMCID: PMC4718279.

14. Rahurkar S, Vest JR, Menachemi N. Despite the spread of health information exchange, there is little evidence of its impact on cost, use, and quality of care. Health affairs 2015; 34(3): 477-483. doi: 10.1377/hlthaff.2014.0729. PubMed PMID: 25732499.

15. Hersh WR, Totten AM, Eden KB, Devine B, Gorman P, Kassakian SZ, Woods SS, Daeges M, Pappas M, McDonagh MS. Outcomes From Health Information Exchange: Systematic Review and Future Research Needs. JMIR medical informatics 2015; 3(4): e39. doi: 10.2196/medinform.5215. PubMed PMID: 26678413; PubMed Central PMCID: PMC4704923.

16. Biondich PG, Grannis SJ. The Indiana network for patient care: an integrated clinical information system informed by over thirty years of experience. J Public Health Manag Pract 2004; (Suppl.): S81-S86. Epub 2005/01/12. doi: 00124784-200411001-00013 [pii]. PubMed PMID: 15643364.

17.Zafar A, Dixon BE. Pulling back the covers: technical lessons of a real-world health information exchange. Studies in health technology and informatics 2007; 129(Pt 1): 488-492. Epub 2007/10/04. PubMed PMID: 17911765.

18. Barnes M. Lessons learned from the implementation of clinical messaging systems. AMIA Annu Symp Proc 2007: 36-40. Epub 2008/08/13. PubMed PMID: 18693793.

19.Dixon BE, Siegel JA, Oemig TV, Grannis SJ. Electronic health information quality challenges and interventions to improve public health surveillance data and practice. Public Health Rep 2013; 128(6): 546-553. Epub 2013/11/02. PubMed PMID: 24179266; PubMed Central PMCID: PMC3804098. 
20.Dixon BE, Grannis SJ, Revere D. Measuring the impact of a health information exchange intervention on provider-based notifiable disease reporting using mixed methods: a study protocol. BMC Med Inform Decis Mak 2013; 13(1): 121. Epub 2013/11/01. doi: 10.1186/1472-6947-13-121. PubMed PMID: 24171799; PubMed Central PMCID: PMC3819468.

21. Indiana Health Information Exchange. ADT Alerts for Reducing ED Admissions: A Case Study Indianapolis, Indiana: Indiana Health Information Exchange; 2013 [cited 2015 May 15]. Available from: http://www.ihie.org/aco-services.

22. Stroupe KT, Smith BM, Hogan TP, St Andre JR, Gellad WF, Weiner S, Lee TA, Burk M, Cunningham F, Piette JD, Rogers TJ, Huo Z, Weaver FM. Medication acquisition across systems of care and patient-provider communication among older veterans. American journal of health-system pharmacy: AJHP: official journal of the American Society of Health-System Pharmacists 2013; 70(9): 804-813. doi: 10.2146/ajhp120222. PubMed PMID: 23592363.

23. Hildreth CJ, Burke AE, Glass RM. JAMA patient page. Inappropriate use of antibiotics. Jama 2009; 302(7): 816. doi: 10.1001/jama.302.7.816. PubMed PMID: 19690318.

24. Shehab N, Lovegrove MC, Geller AI, Rose KO, Weidle NJ, Budnitz DS. US Emergency Department Visits for Outpatient Adverse Drug Events, 2013-2014. Jama 2016; 316(20): 2115-2125. doi: 10.1001/jama.2016.16201. PubMed PMID: 27893129.

25. Johnell K, Klarin I. The relationship between number of drugs and potential drug-drug interactions in the elderly: a study of over 600,000 elderly patients from the Swedish Prescribed Drug Register. Drug safety 2007; 30(10): 911-918. Epub 2007/09/18. PubMed PMID: 17867728.

26. Cooper AL, Jiang L, Yoon J, Charlton ME, Wilson IB, Mor V, Kizer KW, Trivedi AN. Dual-System Use and Intermediate Health Outcomes among Veterans Enrolled in Medicare Advantage Plans. Health services research 2015. doi: 10.1111/1475-6773.12303. PubMed PMID: 25845818.

27. Gaglioti A, Cozad A, Wittrock S, Stewart K, Lampman M, Ono S, Reisinger HS, Charlton ME. Non-VA primary care providers' perspectives on comanagement for rural veterans. Military medicine 2014; 179(11): 1236-1243. doi: 10.7205/MILMED-D-13-00342. PubMed PMID: 25373047.

28. Byrne CM, Mercincavage LM, Bouhaddou O, Bennett JR, Pan EC, Botts NE, Olinger LM, Hunolt E, Banty $\mathrm{KH}$, Cromwell T. The Department of Veterans Affairs' (VA) implementation of the Virtual Lifetime Electronic Record (VLER): findings and lessons learned from Health Information Exchange at 12 sites. International journal of medical informatics 2014; 83(8): 537-547. doi: 10.1016/j.ijmedinf.2014.04.005. PubMed PMID: 24845146.

29. Lyle J, Bouhaddou O, Botts N, Swall M, Pan E, Cullen T, Donahue M, Hsing N. Veterans Health Administration Experience with Data Quality Surveillance of Continuity of Care Documents: Interoperability Challenges for eHealth Exchange Participants. AMIA Annual Symposium proceedings / AMIA Symposium AMIA Symposium 2015; 2015: 870-879. PubMed PMID: 26958223; PubMed Central PMCID: PMC4765662 